\title{
FUNDING DESIGN AND INNOVATION FOR SUSTAINABLE DEVELOPMENT IN AFRICA: A REVIEW OF SOURCES
}

\author{
S.-A. Mitropoulos ${ }^{凶}$, A. Sicko, S. Frilingos, N. Aroh and P. Y. Papalambros \\ University of Michigan, United States of America \\ $\triangle$ mitraris@umich.edu
}

\begin{abstract}
Funding for design impacts the practical ability to address relevant problems. Using public sources, we explore funding aimed at design and business innovations for sustainable development in Africa provided by NGOs, governments, and multinational organizations. We focus on agriculture, energy, sanitation, and urban development, with successful or promising project examples. We conclude that country location, population or economic size do not drive government R\&D spending; agricultural R\&D funding is below targets; and NGOs combine funding with education and skill-building opportunities.
\end{abstract}

Keywords: innovation, sustainability, Africa, sustainable design, funding

\section{Introduction}

Using public sources, this paper explores funding aimed at design and business innovations for sustainable development in Africa provided by NGOs, governments, and multinational organizations. It focuses on agriculture, energy, sanitation, and urban development, with successful or promising project examples. Section 1 discusses the motivation, focus, and scope of this review.

Sustainable development is critical to the quality of life for generations to come. In the classic Brundtland Report definition, sustainable development is “... the development that meets the needs of the present without compromising the ability of future generations to meet their own needs (Imperatives, 1987)." The United Nations (UN) articulated the world's Sustainable Development Goals (SDGs) officially adopted by 193 countries (UN, 2019). Design and innovation are critical enablers for the creation of sustainable products, systems, and services. The design community, encompassing research, education, and practice, has an important role to play in creating systems of collaboration, products, and services at scale. To ascertain the practical ability of the design community to address large-scale sustainability problems, perhaps one question rises above all others: what is the available funding?

This paper attempts to answer that question for Africa, the continent, where access to funding is not as widespread as the rest of the world. Factors such as political and macroeconomic instability, weak infrastructure, poor governance, inhospitable regulatory environments, and ill-conceived investment promotion strategies, have been identified to cause low foreign direct investment in the region (Dupasquier and Osakwe, 2006). Non-Governmental Organizations (NGOs), multinational institutions and local governments attempt to bridge some funding gaps. The UN Conference on Trade and Development (UNCATD) has identified the significance of entrepreneurship as a conductive element 
in the achievement of sustainable development goals (UNCATD, 2017). More specifically, the report's 9th goal focuses on building a resilient infrastructure and promoting inclusive and sustainable industrialization - for which entrepreneurship is an essential driver.

Our work reviews the funding provided by NGOs, governments, and multinational organizations for Research \& Development (R\&D) and for private innovation. Funding areas presented here include agriculture, energy, sanitation, and urban development, with examples of previous successful projects as well as plans for future investments whenever available. We present a coherent summary of some of the largest mechanisms available to designers and entrepreneurs tackling sustainability problems, rather than a complete review of all available funding in those fields.

In the past three decades, several relevant studies have been conducted highlighting funding sources for research and sustainable development. For example, Lewison and May (1997) analysed the efficacy and return of investments on R\&D spending across several countries and, by comparing expenditure patterns, they posited a reduction in gross scientific output with a decline in public research funding. Van Steen (2012) compared R\&D spending for different countries to build key performance indicators (KPIs) applicable to all nations, and determined "relative stability" in R\&D funding across Europe during 2000-2008. The present review aims to incorporate R\&D spending in its assessment, but with a scope narrowed to African countries with funding sources divided into specific categories. It also collates funding sources with their potential benefits and shortcomings, but does not inquire their fiscal success.

Further, there is a negative relationship between the size of financial resources and the success of $R \& D$ projects (Czarnitzki, 2006). Instead of examining this relationship, we describe R\&D funds' availability and distribution mechanisms, again specific to sustainable development in Africa. Voss and Kemp (2015) cover the difficulties advancing specific political agendas due to "reflexive governance." The present report does not analyse political constraints posed upon R\&D projects. However, it discusses the magnitude of governmental investment in innovation. Delonge et al. (2016) explain the value of funding sustainable food systems and stress the importance of increased funding for this sector. Here we include information concerning available funding for agricultural R\&D in Africa, but do not elaborate on its social impact.

Section 2 briefly describes the review methods used, Section 3 provides the key results, followed by discussion and conclusions in Sections 4 and 5, respectively.

\section{Methods - Assumptions}

We investigated the largest mechanisms for distributing funding using the following methodology. We first tried to understand the sources, needs, and uses of funding at each area of interest (e.g., urban development). This step included the review of: (i) studies created by large-scale institutions (e.g., World Bank), which aided us in understanding the needs of funding across the continent; (ii) articles and scientific papers describing case studies that portrayed either the success or failure of an investment strategy, which showed us how funding is commonly used; and (iii) websites of Multinational Organizations (MOs), NGOs, funding competitions and governments, through which we created a short list of potential sources. A selection process followed with criteria (i) the magnitude of the funding available (i.e., minimum of \$50,000) and (ii) the proportion of the investment going into design and innovation. In certain cases, when the distinction of the amount of design-focused funding was unavailable, we decided to make no assumptions to try and estimate it. In the paper we often imply that large-scale projects have a design spending component, even if said component cannot be properly identified. Furthermore, we assumed the terms "R\&D," "entrepreneurship," and "innovation" are interchangeable. In certain sections of the paper, clarifications have been made, as to how one should analyse and explain the available data. Throughout this review, available relevant and well-known datasets were always used. Examples of successful projects and plans for future investments were included when available. Finally, all figures are presented in US Dollars (USD). For funds operating in Euros (EU), a conversion of $1 \mathrm{EU}$ $=1.139$ USD was used as the average exchange rate between 2016- 2018 . 


\section{Results}

\subsection{Funding inflows to Africa}

\subsubsection{Multinational organizations}

Primary sources of funding flowing into Africa are multinational or intergovernmental organizations (IGOs). IGOs are defined as an entity created by treaty, involving two or more nations, to work in good faith, on issues of common interest (Harvard Law School, 2015). We identified the African Development Bank, the United Nations, and the European Union, as well as all the sub-organizations they encompass, as key institutions that strive for sustainability. The World Bank is a major contributor excluded from this review for brevity but included indirectly through its funding to some of the mentioned sources. This section summarizes their initiatives in terms of funding for design and innovation and their respective goals.

The African Development Bank (AfDB) has held a major role in granting funds for innovation and design projects in Africa in the last decade. Through the Boost Africa project, the AfDB along with the European Investment Bank have each committed \$54.5mil, inviting third party investors from the private sector for a total investment of $\$ 218 \mathrm{mil}$. This is expected to propagate further investment estimated at $\$ 1.09 \mathrm{bil}$ to support 1,500 small-to-medium size firms and to create 25,000 direct jobs and at least 75,000 indirect jobs (African Development Bank, 2019). Investments go to sectors that can leverage innovation, with potential to create quality jobs, with youth and women as the main beneficiaries. With regards to the energy sector, the AfDB launched the Power Africa initiative, which will double access to power in sub-Saharan villages. Over the next five years, $\$ 3$ bil is expected to be allocated to the project.

In addition, Africa 50, which works on project design, is sponsored by AfDB and focuses on improving infrastructure by developing bankable projects and catalysing investments into shareholder countries (Africa50, 2016). In 2018, the AfDB and the Nordic Development Fund (2019) created the Urban and Municipal Development Fund, which aims to provide \$14mil in funding for urban development projects within African cities. The African Development Bank's Rural Water Supply and Sanitation Initiative (RWSSI) provides funding for water supply and sanitation projects in rural areas (African Development Bank Group, 2019). It receives donor contributions from Burkina Faso, Canada, Denmark, France, Italy, the Netherlands, and Switzerland amounting to $\sim$ \$200mil, with total available RWSSI project funding of $\$ 210 \mathrm{mil}$.

The UN Development Programme (UNDP) has committed $\$ 3.7$ mil exclusively for the promotion of 750 entrepreneurs across Africa. Contributions come from selected UNDP member countries in the continent, with Nigeria at the forefront, as a state where youth unemployment remained a huge challenge. Initiatives for access to affordable credit have also been undertaken, crafting a more welcoming business environment to start-ups. Further, UNDP Nigeria has started a national programme training over 300 youths in vocational and entrepreneurship skills (Musonda, 2019). Starting in 2015, the UN Department of Economic and Social Affairs grants \$1mil per year to institutions or individuals who have shown leadership and innovation in energy for sustainable development, through a programme called Powering the Future We Want - Recognizing Leadership and Innovative Practices in Energy for Sustainable Development, cofunded by the China Energy Fund Committee (UN DESA, 2015).

Another major multinational means of funding comes from the European Union (EU), which launched the Africa-Europe Alliance for Sustainable Investment and Jobs aiming to create up to 10mil jobs over five years, through the External Investment Plan, putting in \$1.42bil into 52 projects. Under this plan, the Sustainable Business for Africa (SB4A) is a platform which helps identify necessary investment climate reforms to attract private investments, and address challenges, in order to create sustainable jobs for youth and women in Africa (The Africa-EU Partnership, 2018). This initiative aims to provide expertise and assistance to getting innovative projects off the ground.

\subsubsection{Non-Governmental organizations and private initiatives}

The second source of inflows is NGOs. In this section we discuss how some of the most notable private initiatives provide financial capital to small and medium size businesses or tackle the sustainability problems themselves. 


\section{General}

In 2018, the 7th Annual Global Citizen Festival took place in Johannesburg, South Africa, and raised more than \$7bil in commitments, with the primary objective of serving the SDGs as expressions of innovation (Levinson, 2018). This initiative began in 2012 organized by the Global Poverty Project, an NGO working on eradicating extreme poverty. To do so, the importance of design for improved health, education, and infrastructure systems, has been identified. A portion of the funds will become available for investment in design and innovation.

\section{Agriculture}

The importance of agriculture for sustainability goals is well recognized, see Sections 3.2.1, 3.2.2 for further details. Many NGOs have been working in the space, but here we discuss how one of them, the GIF, is using a detailed process to fund and grow sustainable farming practices.

The Global Innovation Fund (GIF) is a non-profit organization which invests in the development, rigorous testing and scaling of innovations targeted at improving the lives of people living in extreme poverty. (Global Innovation Fund, 2017). GIF started a partnership with One Acre Fund (OAF), a non-profit social enterprise, supporting small-holder farmers. GIF awarded \$15mil to OAF to promote widespread food security, with the goal of eliminating hunger in sub-Saharan Africa. The partnership aims at creating $\$ 37$ mil in new farmers' income over a four-year span and an additional \$65mil in the following seasons, as even more African farmers adopt OAF's innovative methods. OAF has designed a business model to make small-scale farming in Africa more efficient, increasing crop yields and diminishing hunger: Asset-based loans finance farmers with seeds and fertilizers, giving them a very flexible repayment system; expansion of farm inputs distribution provides all farmers with walking-distance access to supplies; farmers receive training on modern agricultural techniques throughout the season; and, crop storage solutions are offered along with seminars to expose farmers on the nature of market fluctuations and to help them maximize harvest profits. This program aims at covering over one million farmers by 2020 .

\section{Urban Development}

Urban development is a pressing issue. Africa's share of global urban residents "is projected to grow from 11.3 percent in 2010 to 20.2 percent by 2050" (Center for Strategic and International Studies, 2019). Two key NGOs are major funders of projects aimed exclusively at supporting sustainable urban development. The Cities Alliance is a coalition that yearly calls for proposals for its program, Secure Tenure African Cities, and provides grants of values between $\$ 10,000$ and $\$ 50,000$ to support community organizations creating innovative solutions to urban issues in Africa (Cities Alliance, 2019). The Foundation Fonds Suez is focused on providing funds for projects "promoting the access to essential services," especially in urban and peri-urban areas in developing countries. Its funding has no upper limit, but it can only provide 50\% of the total project budget (Suez, 2019).

\section{Sanitation}

Several private organizations offer funding for sustainable projects aimed toward improving sanitation. The Heineken Africa Foundation partners Heineken breweries with local NGOs and provides funding and directorial assistance (Heineken Africa Foundation, 2019). The program accepts applications from organizations focusing on water, sanitation, and hygiene, and offers up to $\$ 110,000$ per year for each project. The Draper Richards Kaplan Foundation aims to aid populations through 'innovative strategies, systems changing approaches, and disrupting technologies' (Draper Richards Kaplan Foundation, 2019). The foundation seeks entrepreneurs leading projects that promote sustainable impact (including sanitation and water supply) and offers them $\$ 300,000$ over three years. The Water Supply \& Sanitation Collaborative Council's Global Sanitation Fund supports education programs on issues and solutions for open defecation and poor latrines (Water Supply \& Sanitation Collaborative Council, 2019). As of December 2018, the fund had invested $\sim \$ 123.18 \mathrm{mil}$.

\section{Entrepreneurship Competitions}

Across Africa start-up competitions have emerged as a mechanism for receiving funding in the early stage of an innovative business idea. We discuss some of the more prestigious contests. SeedstarsWorld is a venture builder from Switzerland which organizes startup competitions for emerging markets. In sub-Saharan Africa, startups from more than 25 cities compete and the winner from the local 
competition advances to the global finals. In 2016, Giraffe a startup from South-Africa won $\$ 500,000$ for a low-cost automated recruitment service giving wider access to the job market for African job seekers. In 2014, $\$ 330,000$ were awarded to SimplePay, a third-party payment processing company from Nigeria promoting the digitalization of business affairs (Iwuoha, 2017). Innovation Prize for Africa, funded by the African Innovation Foundation, selects 10 nominees with innovative solutions to positively impact Africa (Iwuoha, 2017). The top 3 currently receive a share prize of $\$ 150,000$, while the rest receive a grant of $\$ 5,000$. As an example, in 2017, Ali El-Shafei, won $\$ 100,000$ for his startup, SEMAJIB, which produces a versatile magnetic smart bearing with applications in electricity generation (Iwuoha, 2017).

\section{High-Tech Industry Funding Sources}

High profile funding comes from philanthropic foundations set up by wealthy individuals worldwide. In this section, we discuss funding offered by some Silicon Valley entrepreneurs. Apart from their familiar name, the choice was motivated by the combination of different mechanisms they have set up for dispersing their funds. The Chan Zuckerberg Initiative invested \$24mil in Andela, a startup which trains African engineers and programmers and \$10mil in Bridge International Academies, an education franchise which promotes affordable education in East Africa (Iwuoha, 2017). The Bill \& Melinda Gates Foundation granted \$4.48mil to Sidai Africa in 2016, a social enterprise working in the livestock sector of Kenya. In June 2017, \$2.4mil were awarded to Sanergy, an organization that provides sanitation and hygiene solutions to people living in urban slums. The foundation chooses to donate to organizations that abide by its goals. Its main focus is to improve public health and improve the lives of individuals (Iwuoha, 2017). Omidyar Network a philanthropic investment firm created by the founder of Ebay, Pierre Omidyar, has invested more than $\$ 50$ mil in ventures across Africa. It acts both as a foundation and an impact investment firm, with a focus on re-imagining capitalism and the role philanthropy can play in building a more equitable society (The Chronicle of Philanthropy, 2019). In 2009, it invested \$1.8mil in Bridge International Academies. In 2014, $\$ 400,000$ were granted to BudgIt, a Nigerian start-up which provides access and understanding of public budgets. Following Giraffe's success, the firm hosted two seed funding rounds (The Chronicle of Philanthropy, 2019).

\subsubsection{Single government funding}

The 3rd source of inflows are stand-alone nations. Although all developed nations contribute either directly or indirectly to the sustainable development of Africa, this section analyses the work of USA and Japan, as examples of direct funding.

The US government's international humanitarian organization, USAID, is the main mechanism through which the US aids other countries. USAID oversees an annual Development Innovation Ventures Program, through which it provides funding for projects which offer innovative solutions to philanthropic world issues. Projects can receive anywhere from $\$ 200 \mathrm{k}$ to $\$ 5 \mathrm{mil}$, depending on the stage of development (USAID, 2019). As an example, Burn Manufacturing Ltd became the leading manufacturer and distributor of clean cook stoves in Sub-Saharan Africa by using the $\$ 3$ mil it raised through the program.

In recent years, the Embassy of Japan has made efforts to support clean water and sanitation crises in African countries. To do so, it offers funding from projects aimed at the needs of each country. The Embassy of Japan's Grant Assistance for Grass-roots Human Security Projects offers a maximum of $\$ 92,000$ to grass-roots projects related to sanitation in Botswana (Embassy of Japan in Botswana, 2018). The Embassy of Japan in Uganda operates a similar program which offers a maximum of $\sim \$ 100,000$ to "development-oriented organizations" related to sanitation that specifically assist vulnerable populations such as women and children (Embassy of Japan in Uganda, 2019).

\subsection{InterContinental funding}

Governments are the biggest intercontinental funding source in Africa. The following subsections summarize the amount of funding each nation contributes for $R \& D$, with a more in-depth review on the agricultural sector. A distinction between North and Sub-Saharan regions has been made for agriculture in order to utilize the Agricultural Science and Technology Indicators databank (ASTI, 2019). 


\subsubsection{Net governmental R\&D spending}

Figure 1 shows R\&D investment of select countries. Arguably, not all of R\&D spending goes into projects aimed at sustainable development (e.g., defence R\&D) and that should be kept in mind when interpreting the data. In general, it is a sensible assumption that countries investing heavily in development would aim at a sustainable one.

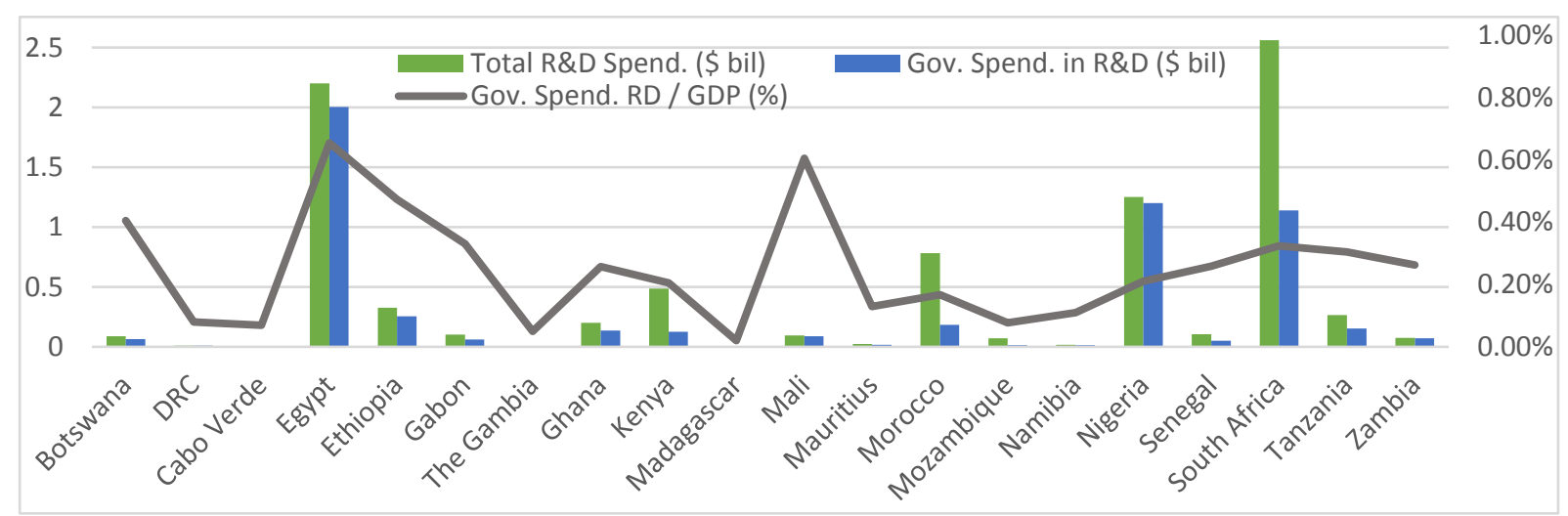

Figure 1. Governmental R\&D spending by country, \$, 2014 (Sources: International Monetary Fund (2014), IndexMundi (2019), and BMJ (Simpkin et al., 2019)

As the graph indicates, net governmental R\&D spending does not appear driven by a country's geographic location, population size, or economic size. In addition, S. Africa and Morocco, which have an active private sector, receive a lot of R\&D funding from non-governmental sources. Egypt is the clear frontrunner for governmental spending, investing the most towards research and development in absolute terms ( $\$ 2$ bil) and as a proportion of GDP. Mali invests significantly above what might be correlated to its size. Madagascar and Gambia spend the least as a proportion of their GDP.

\subsubsection{Government spending on agriculture - Sub-Saharan Africa}

Rates of return for public spending on agricultural R\&D have been uniformly high across the globe, ranging from 30\% in Sub-Saharan Africa to nearly 50\% in East Asia (Benin et al., 2016). As the cases of Tanzania (Fan et al., 2005) and Uganda (Fan and Zhang, 2008) show agricultural R\&D can have a major impact in alleviating poverty, when compared with investment in other public goods.

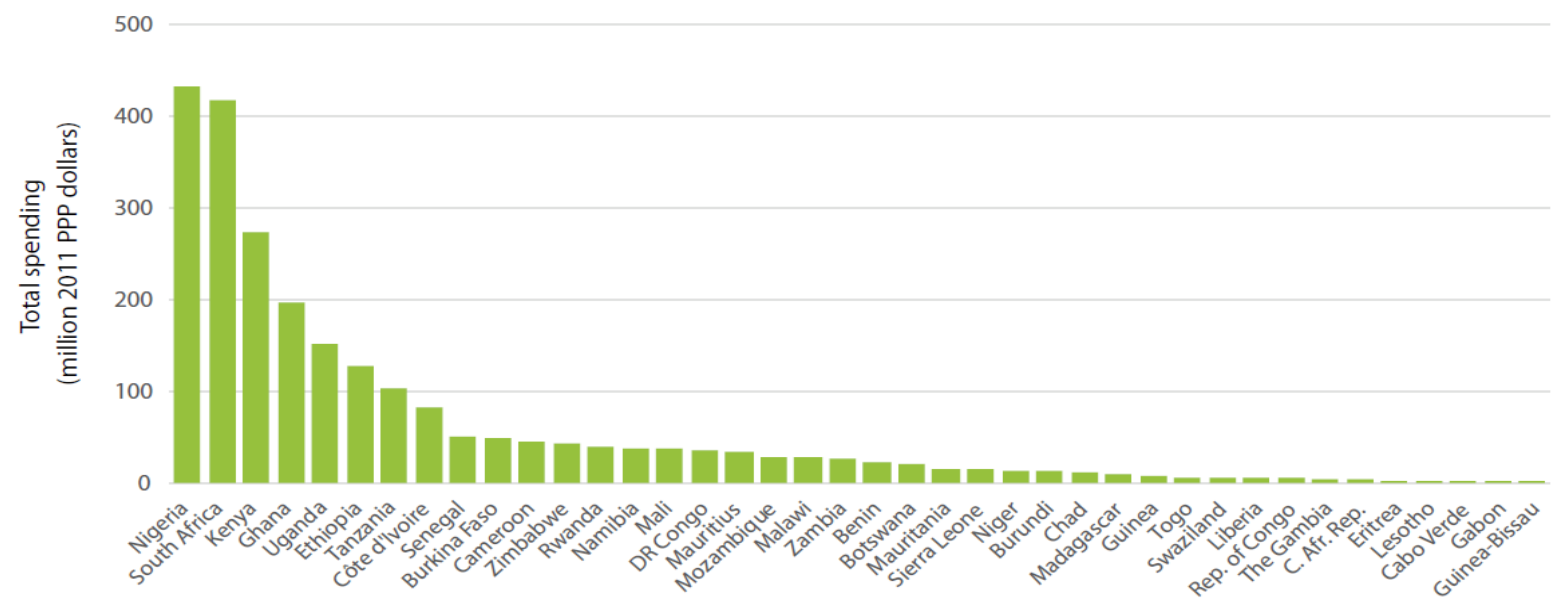

Figure 2. Agricultural R\&D by country, 2014 inflation adj. (Adapted from Beintema et al., 2017)

Figure 2 shows total spending on agricultural R\&D per country. Note that in Sub-Saharan Africa, government spending fails to meet the 1.0\% of Agri. GDP target for 33 out of 40 countries for which data were available. This target was set by African Union's New Partnership for Africa's Development 
(NEPAD) in 2006, with the weighted average dropping from $\sim 0.58 \%$ at the time to $\sim 0.42 \%$ in 2014 , see Figure 3.

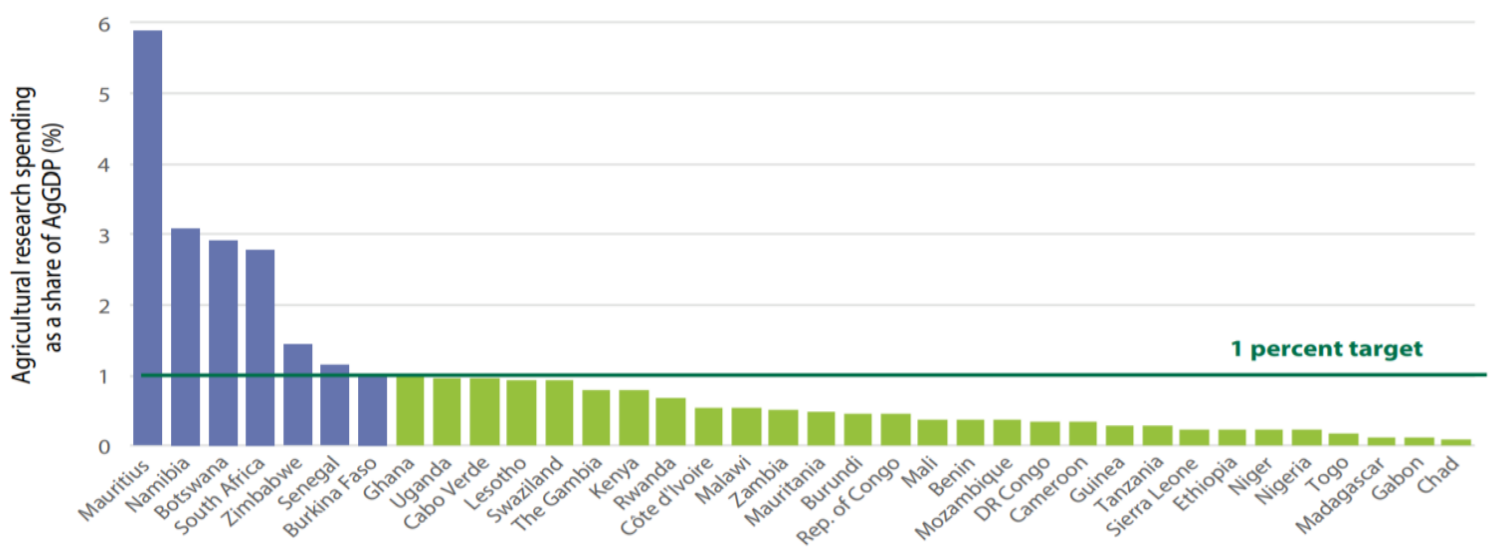

Figure 3. Agricultural research intensity ratios by country, 2014 (Adapted from Beintema et al., 2017)

\subsubsection{Government spending on agriculture - North Africa}

Though government spending on agriculture in developing nations increased between 1980 and 2005, the percentage of GDP in North African countries spent on agriculture declined from $14.76 \%$ to $7.96 \%$ (Fan et al., 2009). Public spending can have a positive influence on farmer income and agricultural productivity, as evidenced specifically in Egypt (Fan et al., 2006). Figure 4 shows total R\&D spending on agriculture in African countries. As seen in Figure 5, these countries all fall below the $1.0 \%$ of Agricultural GDP target referenced in Section 3.2.1

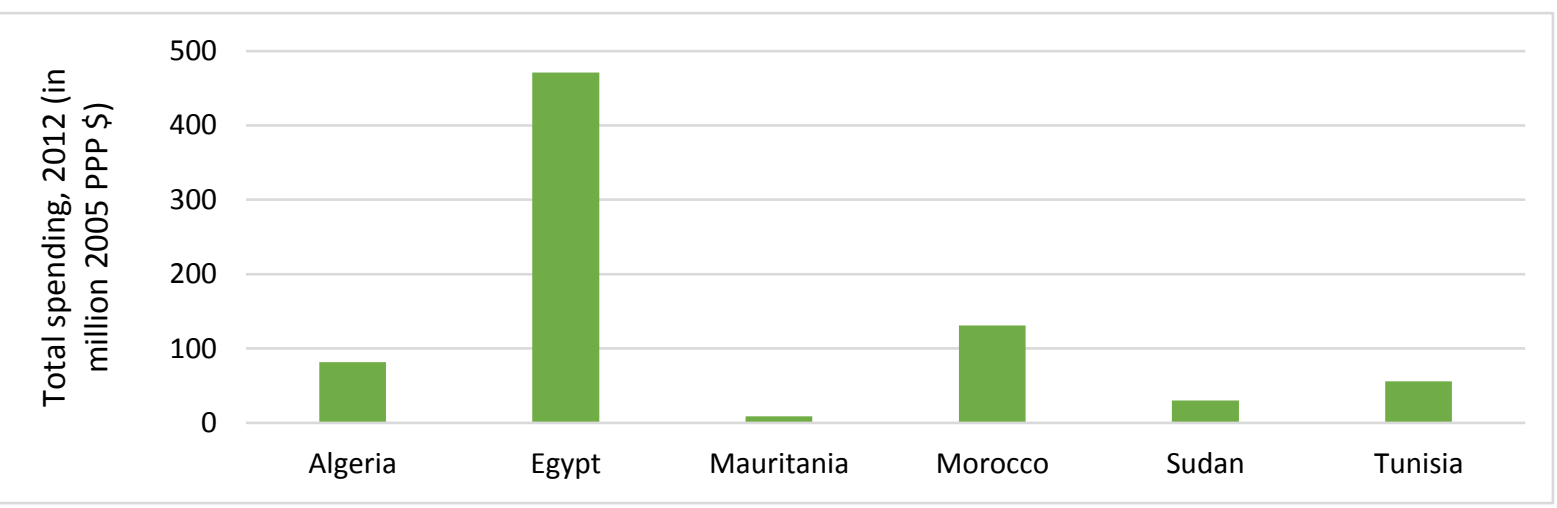

Figure 4. Agricultural R\&D by country, 2012 adj. for inflation (Adapted from Stads, 2015)
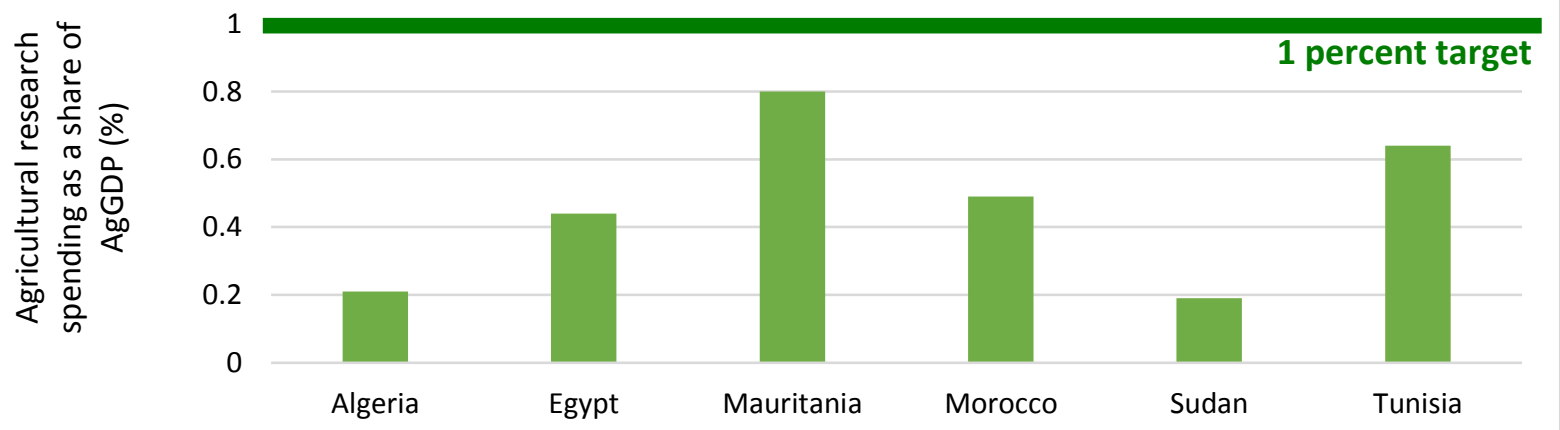

Figure 5. Agricultural research intensity ratios by country, 2012 (Adapted from Stads, 2015) 


\subsubsection{NGOs - TEEP case}

Similar to NGOs working on a global scale, intercontinental organizations also offer large amounts of funding for design and innovation, a notable example being the Tony Elumelu Entrepreneurship Program (TEEP) (Iwuoha, 2017). With a budget of $\$ 100 \mathrm{~m}$ TEEP selects each year 1,000 entrepreneurs from across Africa who have shown great potential for a program of training, mentoring and funding. Participants receive a $\$ 5,000$ seed fund to start up their business. TEEP's vision is to create $1 \mathrm{~m}$ new jobs and $\$ 10 \mathrm{bn}$ in revenues, boosting the African economy (Iwuoha, 2017).

\section{Discussion}

\subsection{Key findings}

As Section 3 displayed, there are several available mechanisms which provide funding for designing new solutions to sustainability problems. Multinational organizations offer much of the available funding, with large-scale projects that span all countries and many industries. Working in parallel with NGOs, these initiatives are the primary means through which designers can receive or use funding to shape impactful solutions to problems in urban development, sanitation, energy and agriculture. NGOs, like GIF, often combine the technical solutions that the funding generates with long term policies, focused on educating the population and developing key skill sets.

IGOs have also created investment projects to increase the rate at which new businesses are generated - with the cooperation of the AfDB and Europe judged as the key "axis" driving forward this attempt. Summing the net effects of the AfDB partnership with the European Investment Bank and of the EU projects mentioned in Section 3.1.1, it is estimated that over \$2bil will go into creating new businesses in Africa. Regarding funding available to existing small and medium scale entrepreneurs, all competitions and funds with philanthropic or sustainability concerns offer low-interest options to growing enterprises across Africa. While it appears that some high-quality innovative businesses can find access to these funds, one must wonder how many other efforts never reach this stage of fund raising due to restricted access to information concerning the application process.

The work of governments reviewed here in some depth for agricultural projects is the major "pain point' identified in terms of funding. Despite the large return on investment and increases in farmer income carried by spending in new agricultural technologies, most countries fall short of the $1 \%$ goal they themselves have set. With the continent's population estimated to reach 1.5 bil by 2030 and 2 bil by 2050 , an increase in national R\&D spending to boost food productivity at large is critical.

\subsection{Limitations}

As mentioned, this paper is not a complete review of all relevant available funding in Africa. It does not cover all mechanisms, industries or available programs. In certain industries the number of active NGOs is too large to monitor, while in other industries databases with governmental budgets for R\&D have not yet been developed. Furthermore, for small-scale design projects, budgets are often not made public, while for large-scale projects, when budgets do exist, distinctions between the money going into the design phase and the implementation process are not available. After all, design principles encompass all aspects of any project work and it is thus a complicated, if not impossible, exercise to separate the funding specifically for them. This paper aimed to serve only as a review of some of the largest and most important mechanisms available.

\subsection{Opportunities for future work}

There are several opportunities for future work. First, one could conduct interviews with business owners, entrepreneurs, and designers to determine how truly accessible the available funding is. Second, one could review how domestic enterprises invest in R\&D aimed at sustainable development. Third, one could investigate how governments spend funds to design their healthcare, sanitation, and energy systems of the future. Fourth, one could analyse the return on investment as a function of funded project size. Fifth, one could work on estimating the funding available for academic collaboration focused on applied research in design - an area which this review has not touched upon, 
but which may provide a great return on investment. Finally, one could look into how the tax environment of a certain country affects the funding provided by NGOs and multinational organizations to domestic projects.

\section{Conclusion}

In summary, we described some of the largest funding opportunities for designers and entrepreneurs that aim at tackling sustainability problems in Africa. Intergovernmental organizations - with AfDB and EU at the forefront - offer funding for large-scale problems, while non-governmental institutions often combine funding with long term policies that aim at creating key skillsets for the local population. We also analysed investment coming from governments both inside and outside the continent. For African governments, R\&D spending does not appear driven by a country's geographic location, population size, or economic size and their funding aimed at agricultural R\&D appears to fall short of the target set. Finally, businesses with innovative solutions can raise capital either through continental funding competitions or directly from global funds.

\section{Acknowledgements}

Partial support of this work by the Donald C. Graham Endowed Chair and the Undergraduate Research Opportunities Program at the University of Michigan is gratefully acknowledged.

\section{References}

Africa50 Infrastructure Fund (2016), Africa50 Infrastructure Fund. [online] Available at: http://www.africa50. com/about-us/our-mission/ (Accessed 1 Nov. 2019).

Heineken Africa Foundation (2019), Our approach - Heineken Africa Foundation. [online] Available at: https://africafoundation.heineken.com/our-approach/ (Accessed 26 Oct. 2019).

African Development Bank (2019), Boost Africa: Empowering Young African Entrepreneurs. [online] African Development Bank - Building today, a better Africa tomorrow. Available at: http://www.afdb.org/en/topicsand-sectors/initiatives-partnerships/boost-africa-empowering-young-african-entrepreneurs (Accessed 1 Nov. 2019).

African Development Bank (2019), Rural Water Supply \& Sanitation Initiative. [online] African Development Bank - Building today, a better Africa tomorrow. Available at: https://www.afdb.org/en/topics-andsectors/initiatives-partnerships/rural-water-supply-sanitation-initiative (Accessed 17 Oct. 2019).

Beintema, N. and Stads, G.-J. (2017), A Comprehensive Overview of Investments and Human Resource Capacity in African Agricultural Research. [online] ASTI led by IFPRI, pp. 4-11. Available at: https://www.asti.cgiar.org/sites/default/files/pdf/SSA-Synthesis-Report-2017.pdf (Accessed 14 Nov. 2019).

Benin, S., McBride, L. and Mogues, T. (2016), "Why do African countries underinvest in agricultural R\&D?", In: Agricultural Research in Africa: Investing in Future Harvests, International Food Policy Research Institute, Washington, DC.

Cities Alliance (2019), About Cities Alliance | Cities Alliance. [online] Available at: https://www.citiesalliance. org/about-cities-alliance (Accessed 14 Nov. 2019).

Center for Strategic and International Studies (2019), Analysis | Center for Strategic and International Studies. [online] Available at: https://www.csis.org/analysis/urbanization-sub-saharan-africa. (Accessed 12 Oct. 2019).

Czarnitzki, D. (2006), "Research and Development in Small and Medium-Sized Enterprises: the Role of Financial Constraints and Public Funding", Scottish Journal of Political Economy, Vol. 53 No. 3, pp. 335-357.

DeLonge, M., Miles, A. and Carlisle, L. (2016), "Investing in the transition to sustainable agriculture", Environmental Science \& Policy, 55, pp. 266-273.

Draper Richards Kaplan Foundation (2019), Apply for Funding | Draper Richards Kaplan Foundation | Supporting passionate, high impact social enterprises. [online] Available at: https://www.drkfoundation.org/ apply-for-funding/ (Accessed 26 Oct. 2019).

Dupasquier, C. and Osakwe, P. (2006), "Foreign direct investment in Africa: Performance, challenges, and responsibilities", Journal of Asian Economics, 17, pp. 241-260. https://doi.org/10.1016/j.asieco.2005.07.002

Embassy of Japan in Botswana (2018), Development Cooperation: Embassy of Japan in Botswana. [online] Available at: https://www.botswana.emb-japan.go.jp/itpr_en/relation-economy.html

Embassy of Japan in Uganda (2019), Embassy of Japan in Uganda. [online] Available at: https://www.ug.embjapan.go.jp/itprtop_en/index.html (Accessed 14 Nov. 2019).

Fan, S. et al. (2006), A Multi-Level Analysis of Public Spending, Growth and Poverty Reduction in Egypt, International Food Policy Research Institute, Washington, DC. 
Fan, S. and Zhang, X. (2008), "Public Expenditure, Growth and Poverty Reduction in Rural Uganda", African Development Review, Vol. 20 No. 3, pp. 466-496.

Fan, S., Nyange, D. and Rao, N. (2005), Public Investment and Poverty Reduction in Tanzania: Evidence from Household Survey Data, International Food Policy Research Institute, Washington, DC.

Fan, S., Omilola, B. and Lambert, M. (2009), Public Spending for Agriculture in Africa: Trends and Composition. Regional Strategic Analysis and Knowledge Support System.

Global Innovation Fund (2017), A New Partnership for Africa's Smallholder Farmers - Global Innovation Fund. [online] Available at: http://www.globalinnovation.fund/a-new-partnership-for-africas-smallholder-farmers/ (Accessed 1 Nov. 2019).

Harvard Law School (2015), Intergovernmental Organizations (IGOs) | Harvard Law School. [online] Harvard Law School. Available at: http://hls.harvard.edu/dept/opia/what-is-public-interest-law/public-service-practicesettings/public-international-law/intergovernmental-organizations-igos/ (Accessed 1 Nov. 2019).

IndexMundi (2019), Research and development expenditure (\% of GDP) - Africa. [online] Available at: http://www.indexmundi.com/facts/indicators/GB.XPD.RSDV.GD.ZS/map/africa (Accessed 1 Nov. 2019).

International Monetary Fund (2014), GDP, Current Prices. [online] Available at: https://www.imf.org/external/ datamapper/NGDPD@WEO/OEMDC/ADVEC/WEOWORLD (Accessed 14 Nov. 2019).

Iwuoha, J. (2017), Smallstarter Africa. [online] Available at: http://www.smallstarter.com/know-the-basics/howto-get-funding-for-your-business-in-africa/ (Accessed 1 Nov. 2019).

Levinson, R. (2018), Financing innovation in Africa: Rebranding the Sustainable Development Goals as an asset class. [online] The Hill. Available at: http://thehill.com/opinion/international/420668-financing-innovationin-africa-rebranding-the-sustainable-development (Accessed 1 Nov. 2019).

Lewison, J.G.G. and May, R.M. (1997), "Government Funding of Research and Development", Science, Vol. 278 No. 5339, pp. 878-880.

Musonda, L. (2019), UNDP invests \$3.7m towards entrepreneurship development in Africa. [online] UNDP. Available at: http://www.ng.undp.org/content/nigeria/en/home/presscenter/articles/2019/undp-invests--3-7m -to-support-entrepreneurs-in-africa.html (Accessed 1 Nov. 2019).

Nordic Development Fund (2019), Urban \& Municipal Development Fund for Africa [NDF C100]. [online] Available at: https://www.ndf.fi/project/urban-municipal-development-fund-africa-ndf-c100-0 (Accessed 14 Nov. 2019).

Simpkin, V. et al. (2019), "Investing in health R\&D: where we are, what limits us, and how to make progress in Africa", BMJ Global Health, [online] Vol. 4 No. 2, p. e001047. Available at: http://gh.bmj.com/content/ 4/2/e001047 (Accessed 1 Nov. 2019).

Stads, G.-J. (2015), Agricultural R\&D in West Asia and North Africa: Recent Investment and Capacity Trends. [online] ASTI led by IFPRI. Available at: http://ebrary.ifpri.org/utils/getfile/collection/p15738coll2/id/129218/ filename/129429.pdf (Accessed 14 Nov. 2019).

Staff (2019), How the Omidyar Network Aims to Reimagine Capitalism (Podcast), [online] The Chronicle of Philanthropy. Available at: http://www.philanthropy.com/article/How-the-Omidyar-Network-Aims/246539 (Accessed 13 Oct. 2019).

Suez (2019), The Foundation SUEZ - SUEZ Group. [online] Available at: https://www.suez.com/en/Who-weare/A-committed-group/The-Fondation-SUEZ (Accessed 12 Oct. 2019).

The Africa-EU Partnership (2018), European Commission unveils new Africa - Europe Alliance for Sustainable Investment and Jobs | The Africa-EU Partnership. [online] Available at: http://www.africa-eupartnership.org/en/stay-informed/news/european-commission-unveils-new-africa-europe-alliancesustainable-investment-and (Accessed 1 Nov. 2019).

UN DESA (2015), New \$US 1 million UN Grant for leadership and innovation in sustainable energy |UN DESA| United Nations Department of Economic and Social Affairs. [online] Available at: http:// www.un.org/en/development/desa/news/sustainable/energy-grant.html (Accessed 1 Nov. 2019).

UN (2019), The Sustainable Development Goals Report (Text), UN, New York.

UNCATD (2017), Promoting Entrepreneurship for Sustainable Development: A Selection of Business Cases From The Empretec Network, United Nations Conference on Trade and Development, New York and Geneva.

USAID (2019), How to Apply | Development Innovation Ventures | U.S. Agency for International Development. [online] Available at: https://www.usaid.gov/div/apply (Accessed 12 Oct. 2019).

Van Steen, J. (2012), Modes of Public Funding of Research and Development: Towards Internationally Comparable Indicators. OECD Science, Technology and Industry Working Papers.

Water Supply \& Sanitation Collaborative Council (2019), Global Sanitation Fund - WSSCC. [online] Available at: https://www.wsscc.org/global-sanitation-fund/ (Accessed 26 Oct. 2019). 